\title{
Caseload as a factor for outcome in aneurysmal subarachnoid hemorrhage: a systematic review and meta-analysis
}

\author{
A systematic review
}

\author{
Hieronymus D. Boogaarts, M.D., ${ }^{1}$ Martinus J. van Amerongen, M.D., ${ }^{1}$ \\ Joost de Vries, M.D., Ph.D., ${ }^{1}$ Gert P. Westert, Ph.D., ${ }^{2}$ \\ André L. M. Verbeek, M.D., Ph.D., ${ }^{3}$ J. André Grotenhuis, M.D., Ph.D., 1 \\ and Ronald H. M. A. Bartels, M.D., Ph.D. ${ }^{1}$
}

Departments of ${ }^{I}$ Neurosurgery and ${ }^{3}$ Epidemiology and Biostatistics, and ${ }^{2}$ Scientific Institute for Quality of
Healthcare (IQ Healthcare), and Radboud University Nijmegen Medical Centre, Nijmegen, The Netherlands

Object. Increasing evidence exists that treatment of complex medical conditions in high-volume centers is found to improve outcome. Patients with subarachnoid hemorrhage (SAH), a complex disease, probably also benefit from treatment at a high-volume center. The authors aimed to determine, based on published literature, whether a higher hospital caseload is associated with improved outcomes of patients undergoing treatment after aneurysmal subarachnoid hemorrhage.

Methods. The authors identified studies from MEDLINE, Embase, and the Cochrane Library up to September 28,2012 , that evaluated outcome in high-volume versus low-volume centers in patients with SAH who were treated by either clipping or endovascular coiling. No language restrictions were set. The compared outcome measure was in-hospital mortality. Mortality in studies was pooled in a random effects meta-analysis. Study quality was reported according to the GRADE (Grading of Recommendations Assessment, Development and Evaluation) criteria.

Results. Four articles were included in this analysis, representing 36,600 patients. The quality of studies was graded low in 3 and very low in 1. Meta-analysis using a random effects model showed a decrease in hospital mortality (OR 0.77 [95\% CI 0.60-0.97]; $\mathrm{p}=0.00 ; \mathrm{I}^{2}=91 \%$ ) in high-volume hospitals treating SAH patients. Sensitivity analysis revealed the relative weight of the 1 low-quality study. Removal of the study with very low quality increased the effect size of the meta-analysis to an OR of $0.68\left(95 \%\right.$ CI $\left.0.56-0.84 ; \mathrm{p}=0.00 ; \mathrm{I}^{2}=86 \%\right)$. The definition of hospital volume differed among studies. Cutoffs and dichotomizations were used as well as division in quartiles. In 1 study, low volume was defined as 9 or fewer patients yearly, whereas in another it was defined as fewer than 30 patients yearly. Similarly, 1 study defined high volume as more than 20 patients annually, and another defined it as more than 50 patients a year. For comparability between studies, recalculation was done with dichotomized data if available. Cross et al., 2003 (low volume $\leq 18$, high volume $\geq 19$ ) and Johnston, 2000 (low volume $\leq 31$, high volume $\geq 32$ ) provided core data for recalculation. The overall results of this analysis revealed an OR of 0.85 (95\% CI 0.72-0.99; $\left.\mathrm{p}=0.00 ; \mathrm{I}^{2}=87 \%\right)$.

Conclusions. Despite the shortcomings of this study, the mortality rate was lower in hospitals with a larger caseload. Limitations of the meta-analysis are the not uniform cutoff values and uncertainty about case mix. (http://thejns.org/doi/abs/10.3171/2013.9.JNS13640)

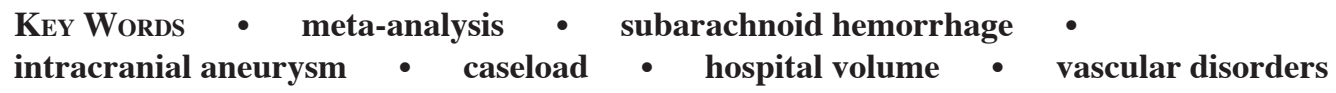

$\mathrm{C}$ ASELOAD in relation to outcome has been a topic of an increasing number of publications in the medical literature. Hospital volume and outcome are generally more strongly associated for medical conditions that require more complex management. ${ }^{15,35}$ Regulations for centralization of specialized care are emerging from the medical field, government, and health insurance companies. For treatment of patients with ruptured cerebral

Abbreviations used in this paper: GRADE = Grading of Recommendations Assessment, Development and Evaluation; SAH = subarachnoid hemorrhage. aneurysms, a complex disease, several studies with contrasting results have appeared. ${ }^{6,7,16}$ The purpose of this study was to perform a meta-analysis to investigate the relationship between caseload and outcome in series of patients undergoing treatment of aneurysms after subarachnoid hemorrhage (SAH). The treatment modality could be either clipping or coiling. Hospital mortality was chosen as the outcome measure.

\section{Methods}

The meta-analysis was constructed according to the 
MOOSE (meta-analysis of observational studies in epidemiology) guidelines. ${ }^{37}$ An independent experienced librarian searched the literature published in MEDLINE, Embase, and the Cochrane Library through September 28,2012 , using the following key words: $\mathrm{SAH}$, case load, outcome, aneurysm. No language restrictions were used. For a detailed search string please see Table 1. Studies were eligible for inclusion if they met the following criteria: 1) evaluated in-hospital mortality after open and/or endovascular treatment in patients with ruptured intracranial aneurysms, 2) compared low-volume with high-volume hospitals, and 3) provided an odds ratio or core data to calculate an odds ratio. If the same data were used in more than one article, the most recent or largest data set was included. Duplicate papers were removed. Conference abstracts, reviews, editorials, meta-analyses, and animal studies were also excluded. Studies were excluded if they did not provide postoperative mortality rates in patients treated for ruptured aneurysms with endovascular coiling or surgical clipping in relation to volume. Two researchers (M.v.A. and H.D.B.) independently reviewed the titles and abstracts of the articles. In the case of disagreement during this process, a third reviewer (J.d.V.) was asked. From the remaining articles, full-text versions were obtained and were independently evaluated by the same researchers. From the full-text versions, reference screening was performed to evaluate other possible studies. A data recording form, developed for this purpose, was used by 2 authors (M.v.A. and R.B.) for independent data extraction from each study. After extraction, data were reviewed and were compared by the first author. Disagreement was solved by consensus. Assessment of the methodological quality of the studies included in the review was done according to the GRADE guidelines. ${ }^{14}$ The studies were independently assessed by the 2 researchers (R.B. and J.d.V.) for limitations, indirectness, inconsistency, imprecision, and publication bias. Overall in-hospital mortality after open surgical and/or endovascular treatment in patients with SAH was defined as the primary end point.

\section{Statistical Analysis}

To identify potential associations between hospital volume and mortality, a pooled odds ratio with $95 \%$ confidence intervals was constructed. The significance of the overall odds ratio was determined by the z-test. The Type I error was set at 0.05 . The tests were 2 -tailed. The random effects model was used as the preferable approach to manage potential between-study heterogeneity. Statistical heterogeneity across studies was quantified using the $\mathrm{I}^{2}$ statistic. This statistic describes the percentage of total variation across studies that is due to heterogeneity rather than chance. ${ }^{19}$ The $\mathrm{I}^{2}$ statistic was calculated from $\mathrm{Q}$ (the Cochran heterogeneity statistic) as follows: $\mathrm{I}^{2}=100 \% \times$

\section{TABLE 1: Search strategy and results of MEDLINE, Embase, and Cochrane Library searches*}

\begin{tabular}{|c|c|c|c|c|}
\hline \multirow[b]{2}{*}{ Step } & \multirow[b]{2}{*}{ Search } & \multicolumn{3}{|c|}{ No. of Studies } \\
\hline & & PubMed & Cochrane & Embase \\
\hline 1 & subarachnoid hemorrhage[MeSH:noexp] & 14,980 & 375 & 26,035 \\
\hline 2 & $\begin{array}{l}\text { subarachnoid haemorrhage[tiab] OR (subarachnoid[tiab] AND hemorrhage[tiab]) OR subarachnoid hemor- } \\
\text { rhage[tiab] OR subarachnoid haemorrhages[tiab] OR subarachnoid hemorrhages[tiab] OR SAH[tiab] OR } \\
\text { SAHs[tiab] OR subarachnoid hematoma[tiab] OR subarachnoid bleeding[tiab] }\end{array}$ & 17,916 & 930 & 22,474 \\
\hline 3 & Step 1 OR Step 2 & 22,212 & 1,214 & 31,404 \\
\hline 4 & intracranial aneurysm[MeSH] & 19,901 & 333 & 23,962 \\
\hline 5 & (brain aneurysm[tiab] OR brain aneurysms[tiab] OR cerebral aneurysm[tiab] OR cerebral aneurysms[tiab]) & 4,006 & 372 & 5,034 \\
\hline 6 & Step 4 OR Step 5 & 20,790 & 492 & 30,331 \\
\hline 7 & rupture*[tiab]† & 86,436 & 2,304 & 102,580 \\
\hline 8 & Step 6 AND Step 7 & 5,423 & 193 & 4,981 \\
\hline 9 & Step 3 OR Step 8 & 24,675 & 985 & 33,626 \\
\hline 10 & "neurosurgery/statistics and numerical data"[MeSH]‡ & 1,923 & 13 & 964 \\
\hline 11 & workload[MeSH] & 13,778 & 487 & 24,873 \\
\hline 12 & $\begin{array}{l}\text { high volume[tiab] OR high volumes[tiab] OR high-volume[tiab] OR higher volume[tiab] OR higher volumes[tiab] } \\
\text { OR low volumes[tiab] OR lower volumes[tiab] OR low-volume[tiab] OR lower-volume[tiab] OR workload[tiab] } \\
\text { OR (work[tiab] AND load[tiab]) OR caseload[tiab] OR caseloads[tiab] OR surgeon volume[tiab] OR work- } \\
\text { loads[tiab] OR surgical volume[tiab] OR operative volume[tiab] OR surgical volumes[tiab] OR operative vol- } \\
\text { umes[tiab] OR (case[tiab] AND load[tiab]) OR case volume[tiab] OR case volumes[tiab] OR operation rate } \\
\text { [tiab] OR operation rates[tiab] OR hospital volume[tiab] OR hospital volumes[tiab] OR highest-volume[tiab] } \\
\text { OR highest-volumes[tiab] }\end{array}$ & 42,833 & 24,767 & 56,421 \\
\hline 13 & Step 10 OR Step 11 OR Step 12 & 54,269 & 24,778 & 71,050 \\
\hline 14 & Step 9 AND Step 13 & 76 & 35 & 152 \\
\hline
\end{tabular}

${ }^{*}$ MeSH = Medical Subject Headings; noexp = no explosion of MeSH heading; tiab = title/abstract.

$\dagger$ The asterisk in this field indicates that rupture was a major topic of these articles.

$\ddagger$ Quotation marks indicate that the entire phrase was searched. 


\section{Caseload and outcome in SAH}

(Q - df)/Q. For sensitivity analysis, each study was removed in turn from the total, and the remaining studies were reanalyzed to identify the impact of each study on the overall result. Publication bias was graphically assessed using a funnel plot. In addition, Egger's test was used for quantitative assessment. Comprehensive MetaAnalysis software (version 2.2.046, BIOSTAT) was used for statistical analysis.

\section{Results}

\section{Included Studies}

The initial search revealed 263 studies (Table 1). After removing duplicate studies, abstracts from 211 studies, including one found by reference screening, ${ }^{36}$ were evaluated. One hundred seventy-nine studies were excluded because they did not meet inclusion criteria. Thirty-two studies were considered for full-text evaluation. ${ }^{1-13,16-18,20-23 \text {, }}$ 25-27,30-34,36,38-40 Twenty-eight studies were excluded for the following reasons: 2 were review studies, ${ }^{34,40} 5$ had insufficient data, $, 5,8,10,36,393$ included treatment of unruptured aneurysms, $, 321,338$ contained single-center data, ${ }^{4,6,11-13,22,30,31} 3$ had no caseload comparison, ${ }^{18,25,26} 2$ did not have mortality as an outcome, ${ }^{1,20} 1$ was an editorial,,${ }^{17} 3$ had overlapping source data, 2,7,32 and 1 included only patients older than 65 years. ${ }^{38}$ Therefore, 4 studies were included for final analysis (Fig. 1).,16,23,27 The selected studies involved a total of 36,600 patients. Retrospective data from databases were used in 3 studies, and 1 evaluated data from a survey (Table 2). The treatment modality was clipping or endovascular coiling in 3 studies, and 1 study only evaluated open surgical results. Hospital volume definitions differed between studies. Cutoffs and dichotomizations were used as well as division in quartiles. Low volume was defined as 9 or fewer patients yearly in 1 study and as fewer than 30 in another. Similarly, high volume was defined as more than 20 patients annually in 1 study and as more than 50 patients annually in another. The definitions used in the articles were used for primary analysis. The methodological quality of 3 articles was graded as low and 1 as very low. Up-rating was not performed (Table 3).

\section{Meta-Analysis}

The overall meta-analysis suggested a significant relationship for in-hospital mortality for SAH patients in favor of high-volume hospitals (OR 0.77 [95\% CI 0.60-0.97] random model) (Fig. 2A). The Q value for the test of heterogeneity was $33.2(\mathrm{p}=0.0001)$, indicating heterogeneity and justifying the use of the random effects analysis. The

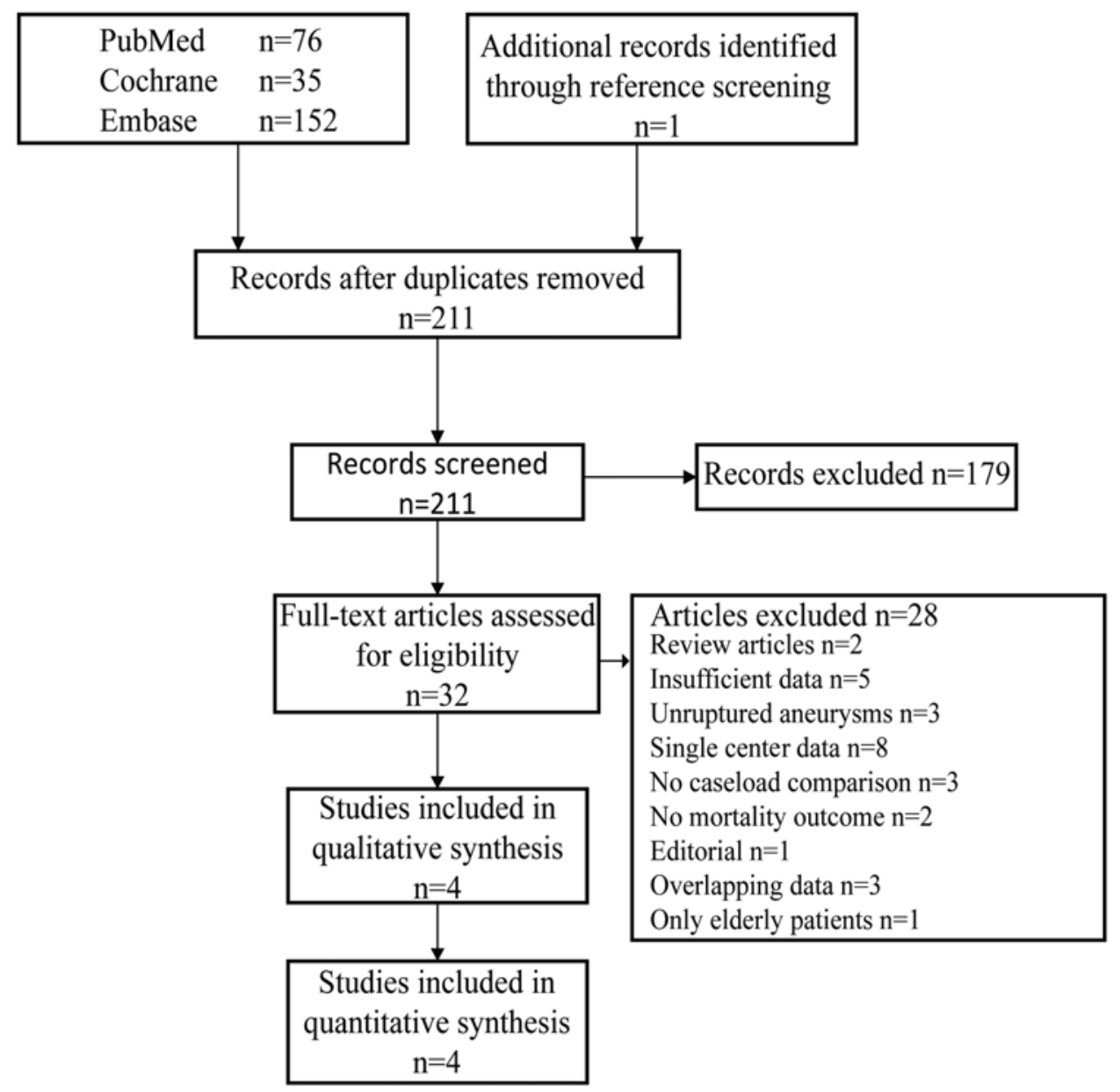

FIG. 1. Chart showing the results of the literature search. 
TABLE 2: Characteristics of the studies

\begin{tabular}{|c|c|c|c|c|}
\hline \multirow[b]{2}{*}{ Authors \& Year } & \multirow[b]{2}{*}{ Source, Years } & \multirow[b]{2}{*}{ Treatment modality } & \multicolumn{2}{|c|}{ Definition of $\mathrm{Vol}$} \\
\hline & & & Low & High \\
\hline Johnston, 2000 & $\begin{array}{l}\text { University Health Systems Consortium, } \\
\text { 1994-1997 }\end{array}$ & clipping \& coiling & 0-16 (1st quartile) & $>45$ (4th quartile) \\
\hline Cross et al., 2003 & database (California \& Florida), 1998-2000 & clipping \& coiling & $0-9$ (1st quartile) & 36-158 (4th quartile) \\
\hline Hattori et al., 2007 & Survey Japan, 2003 & clipping & $<30$ (1st group) & $\geq 50$ (3rd group) \\
\hline Leake et al., 2011 & $\begin{array}{l}\text { Nationwide Inpatient Sample (NIS) database, } \\
\text { 2001-2008 }\end{array}$ & clipping \& coiling & $\leq 20$ & $>20$ \\
\hline
\end{tabular}

sensitivity analysis revealed a relative weight of the study by Hattori et al. ${ }^{16}$ Including this study and subsequently removing others by alternation lifted the point estimate slightly upward. The result was not statistically significant. However, removal of this study with very low quality (see Table 3) increased the effect size to an OR 0.68 (95\% CI 0.56-84) (Fig. 2B). ${ }^{7}$ The funnel plot suggested publication bias; however, the Egger's test (intercept 1.21, $\mathrm{p}=0.86$ [2-tailed]) did not (Fig. 3). This result should be interpreted with great caution, because of the very limited number of studies. For comparability between studies, recalculation was done with dichotomized data if available (Table 4). Cross et al. (low volume $\leq 18$ patients, high volume $\geq$ 19 patients) and Johnston (low volume $\leq 31$ patients, high volume $\geq 32$ patients) provided core data for recalculation. ${ }^{9,23}$ The overall results of this analysis of the 4 studies revealed an OR of 0.85 (95\% CI 0.72-0.99).

\section{Discussion}

This meta-analysis demonstrates that treatment of patients with ruptured intracranial aneurysms in high-volume centers is associated with lower in-hospital mortality compared with low-volume centers. The positive correlation between a high-volume center and outcome could be attributed to several factors. First of all, high-volume centers more likely have a subspecialized team working in a multidisciplinary setting. A well-functioning and experienced team consisting of neurologists, neurosurgeons, neuroradiologists, neurointerventionalists, neurorehabilitation specialists, neurointensivists, and a dedicated nursing team will certainly contribute to a better outcome.$^{5,8,24}$ A potential drawback of centralization would be the risk of rehemorrhage and death during transfer; however, as investigated by Bardach et al., the organization of SAH care in high-volume hospitals is justified not only for costeffectiveness but also for patient outcome. ${ }^{1}$
Several limitations of this study should be mentioned. First, the study data mainly rely on retrospective data based on hospital coding and can therefore be biased. Second, the patients within the studies were a selection of a population mainly from northern US databases. Infrastructural and geological characteristics might not be applicable to other countries. Third, the treatment modality might be associated with outcome and with hospital volume; centers also providing endovascular treatment have better results because of the lower associated morbidity and mortality rates as found in the International Subarachnoid Aneurysm Trial (ISAT) and recently the Barrow Ruptured Aneurysm Trial (BRAT). ${ }^{28,29}$ High-volume centers are more likely to have an endovascular treatment modality and thus will probably have better results., ${ }^{9,13}$ Fourth, we used unadjusted core data from the studies to attain comparability, since adjustment for case mix was not done or it was done in different ways. Hattori et al. corrected for initial clinical grade, but not for comorbidities and did not find a significant difference in the distribution of the World Federation of Neurosurgical Societies grade on admission between the different volume groups. ${ }^{16}$ Cross et al. corrected for comorbidities but not for initial grade. ${ }^{9}$ Leake et al. did not correct for comorbid conditions nor initial grade..$^{27}$ Johnston corrected for age but not for comorbidities or initial grade. ${ }^{23}$ Fifth, the distinction between low volume and high volume is artificial. As shown, a uniform cutoff is not provided. At best, an approximate cutoff could be estimated. However, recalculation with dichotomized data revealed comparable results, centering the possible distinction between high volume and low volume around 20-30 patients yearly. Sixth, in-hospital mortality was chosen as the primary outcome measure; although commonly used as a measure of quality of care, it can be influenced by discharge policies. Better would be a more detailed outcome measure such as the modified Rankin Scale score; unfortunately, only the study by Hattori et al. provided these data. ${ }^{16}$ Finally, transfer of pa-

TABLE 3: GRADE evidence profile

\begin{tabular}{|c|c|c|c|c|c|c|c|c|}
\hline Authors \& Year & Study Design & Limitations & Inconsistency & Indirectness & Imprecision & Publication Bias & Magnitude of Effect & Quality \\
\hline Johnston, 2000 & observational & none & none & none & none & none & none & low \\
\hline Cross et al., 2003 & observational & none & none & none & none & none & none & low \\
\hline Hattori et al., 2007 & observational & serious & none & none & none & none & none & very low \\
\hline Leake et al., 2011 & observational & none & none & none & none & none & none & low \\
\hline
\end{tabular}




\section{Caseload and outcome in $\mathrm{SAH}$}

A

\section{Study name}

Johnston, 2000

Cross et al., 2003

Hattori et al., 2007

Leake et al., 2011

Overall
Statistics for each study

$\begin{array}{ccc}\begin{array}{c}\text { Lower } \\ \text { limit }\end{array} & \begin{array}{c}\text { Upper } \\ \text { limit }\end{array} & \begin{array}{c}\text { Z-Value } \\ 0.550\end{array} \\ 0.865 & -3.209 \\ 0.517 & 0.664 & -8.381 \\ 0.915 & 1.322 & 1.016 \\ 0.719 & 0.859 & -5.323 \\ 0.604 & 0.972 & -2.190\end{array}$

Odds ratio and $95 \% \mathrm{Cl}$

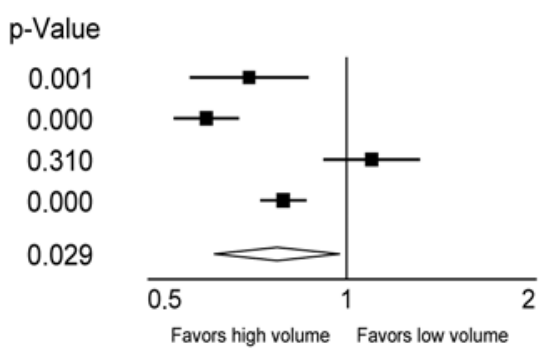

Odds ratio $(95 \% \mathrm{Cl})$

with study removed

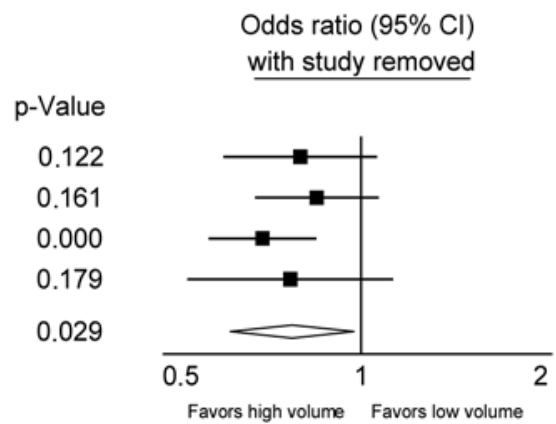

Statistics with study removed

Lower Upper
limit
limit

0.588

0.665

0.555

0.512

0.604
Z-Value

$-1.546$

$-1.401$

$-3.574$

$-1.345$

$-2.190$

FIG. 2. Forest plots showing results of the meta-analysis of high versus low volume hospitals (A) and sensitivity analysis (B). The squares indicate the mean, the whiskers indicate the $95 \% \mathrm{Cl}$, and the diamonds indicate the pooled estimate (the width of the diamond represents the $95 \% \mathrm{Cl}$ ).

tients might cause bias. Patients who were likely to die were not transferred to a high-volume center for treatment; conversely, transferred patients tended to do better than patients in community hospitals. ${ }^{13,41}$

This study does not answer the question of how much patients should be treated by a single surgeon or neurointerventionalist to obtain the best result. ${ }^{3,26,39}$ As previously stated, the results of treatment are not merely the merits of one specialist but the chain of care. In the scope of quality of care and the increasing demand for centralization, volume number alone is not sufficient as a parameter to guide these developments. Caseload should be seen as one of the cofactors related to outcome.

\section{Conclusions}

Despite shortcomings of the included studies but based on the best available data at this moment, mortality is lower in hospitals that treat a high volume of patients with SAH. Although a true cutoff value to distinguish between high- and low-volume centers could not be given, it probably can be centered between 20 and 30 patients annually. An explanation for the relationship between outcome and caseload could be a multidisciplinary approach resulting in a team dedicated to the care of patients with $\mathrm{SAH}$. As such, the number of treated patients yearly cannot be used as a sole measure for quality of care.

\section{Acknowledgment}

We would like to thank Alice Tillema for the literature search.

\section{Disclosure}

The authors report no conflict of interest concerning the materials or methods used in this study or the findings specified in this paper.

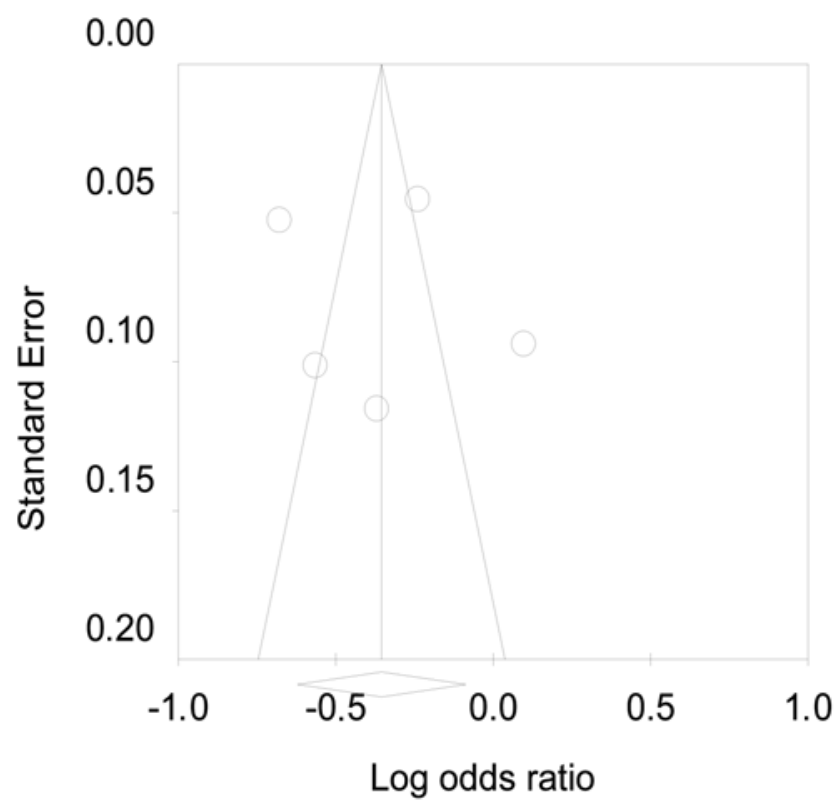

FIG. 3. Funnel plot. The points correspond to the treatment effects from individual studies, the diagonal lines show the expected $95 \%$ confidence intervals around the summary estimate. Odds ratios are plotted on a logarithmic scale. 
TABLE 4: Study core data*

\begin{tabular}{|c|c|c|c|c|c|c|c|c|}
\hline \multirow[b]{2}{*}{ Authors \& Year } & \multicolumn{4}{|c|}{ High-Vol Hospitals } & \multicolumn{4}{|c|}{ Low-Vol Hospitals } \\
\hline & Total & Deaths & Alive & Mortality & Total & Deaths & Alive & Mortality \\
\hline Johnston, 2000 & $4693(7573)$ & $1000(1730)$ & 3693 (5843) & $21.3 \%(22.8 \%)$ & 408 (1961) & $115(489)$ & $293(1472)$ & $28.2 \%(24.9 \%)$ \\
\hline Hattori et al., 2007 & 2522 & 257 & 2265 & $10.2 \%$ & 2631 & 246 & 2385 & $9.4 \%$ \\
\hline Leake et al., 2011 & 8247 & 1004 & 7243 & $10.6 \%$ & 8556 & 1283 & 7273 & $14.2 \%$ \\
\hline
\end{tabular}

* Values are the number of patients unless specified otherwise. Numbers in parentheses indicate the number of patients if dichotomization was used (see text).

Author contributions to the study and manuscript preparation include the following. Conception and design: Boogaarts. Acquisition of data: Boogaarts. Analysis and interpretation of data: Boogaarts, de Vries, Verbeek. Drafting the article: Boogaarts, Westert. Critically revising the article: all authors. Reviewed submitted version of manuscript: all authors. Approved the final version of the manuscript on behalf of all authors: Boogaarts. Statistical analysis: Boogaarts, Verbeek. Administrative/technical/material support: van Amerongen. Study supervision: Bartels.

\section{References}

1. Bardach NS, Olson SJ, Elkins JS, Smith WS, Lawton MT, Johnston SC: Regionalization of treatment for subarachnoid hemorrhage: a cost-utility analysis. Circulation 109:22072212, 2004

2. Bardach NS, Zhao S, Gress DR, Lawton MT, Johnston SC: Association between subarachnoid hemorrhage outcomes and number of cases treated at California hospitals. Stroke 33: 1851-1856, 2002

3. Barker FG II, Amin-Hanjani S, Butler WE, Ogilvy CS, Carter BS, Batjer HH: In-hospital mortality and morbidity after surgical treatment of unruptured intracranial aneurysms in the United States, 1996-2000: the effect of hospital and surgeon volume. Neurosurgery 52:995-1009, 2003

4. Benes V III, Mitchell P, Molyneux AJ, Renowden SA: Endovascular coiling in 131 patients with low complication rate justifies treating most unruptured intracranial aneurysms. Cent Eur Neurosurg 71:1-7, 2010

5. Berman MF, Solomon RA, Mayer SA, Johnston SC, Yung PP: Impact of hospital-related factors on outcome after treatment of cerebral aneurysms. Stroke 34:2200-2207, 2003

6. Bunc G, Ravnik J, Seruga T: Treatment of ruptured intracranial aneurysms: report from a low-volume center. Wien Klin Wochenschr 118 (Suppl 2):6-11, 2006

7. Cowan JA Jr, Dimick JB, Wainess RM, Upchurch GR Jr, Thompson BG: Outcomes after cerebral aneurysm clip occlusion in the United States: the need for evidence-based hospital referral. J Neurosurg 99:947-952, 2003

8. Cowan JA Jr, Ziewacz J, Dimick JB, Upchurch GR Jr, Thompson BG: Use of endovascular coil embolization and surgical clip occlusion for cerebral artery aneurysms. J Neurosurg 107:530-535, 2007

9. Cross DT III, Tirschwell DL, Clark MA, Tuden D, Derdeyn $\mathrm{CP}$, Moran CJ, et al: Mortality rates after subarachnoid hemorrhage: variations according to hospital case volume in 18 states. J Neurosurg 99:810-817, 2003

10. Crowley RW, Yeoh HK, Stukenborg GJ, Ionescu AA, Kassell NF, Dumont AS: Influence of weekend versus weekday hospital admission on mortality following subarachnoid hemorrhage. Clinical article. J Neurosurg 111:60-66, 2009

11. Gnanalingham KK, Apostolopoulos V, Barazi S, O’Neill K: The impact of the international subarachnoid aneurysm trial
(ISAT) on the management of aneurysmal subarachnoid haemorrhage in a neurosurgical unit in the UK. Clin Neurol Neurosurg 108:117-123, 2006

12. Goldschlager T, Selvanathan S, Walker DG: Can a "novice" do aneurysm surgery? Surgical outcomes in a low-volume, nonsubspecialised neurosurgical unit. J Clin Neurosci 14:10551061, 2007

13. Gordhan A, Invergo D: Stent-assisted aneurysm coil embolization: safety and efficacy at a low-volume center. Neurol Res 33:942-946, 2011

14. Guyatt GH, Oxman AD, Vist GE, Kunz R, Falck-Ytter Y, Alonso-Coello P, et al: GRADE: an emerging consensus on rating quality of evidence and strength of recommendations. BMJ 336:924-926, 2008

15. Hannan EL, Popp AJ, Tranmer B, Fuestel P, Waldman J, Shah D: Relationship between provider volume and mortality for carotid endarterectomies in New York state. Stroke 29:22922297, 1998

16. Hattori N, Katayama Y, Abe T, Japan Neurosurgical Society: Case volume does not correlate with outcome after cerebral aneurysm clipping: a nationwide study in Japan. Neurol Med Chir (Tokyo) 47:95-101, 2007

17. Heros RC: Editorial. Case volume and mortality. J Neurosurg 99:805-806, 2003

18. Higashida RT, Lahue BJ, Torbey MT, Hopkins LN, Leip E, Hanley DF: Treatment of unruptured intracranial aneurysms: a nationwide assessment of effectiveness. AJNR Am J Neuroradiol 28:146-151, 2007

19. Higgins JP, Thompson SG, Deeks JJ, Altman DG: Measuring inconsistency in meta-analyses. BMJ 327:557-560, 2003

20. Hoh BL, Chi YY, Lawson MF, Mocco J, Barker FG II: Length of stay and total hospital charges of clipping versus coiling for ruptured and unruptured adult cerebral aneurysms in the Nationwide Inpatient Sample database 2002 to 2006. Stroke 41: 337-342, 2010

21. Hoh BL, Rabinov JD, Pryor JC, Carter BS, Barker FG II: Inhospital morbidity and mortality after endovascular treatment of unruptured intracranial aneurysms in the United States, 1996-2000: effect of hospital and physician volume. AJNR Am J Neuroradiol 24:1409-1420, 2003

22. Invergo D, Gordhan A: Endovascular treatment of cerebral aneurysms at a low-volume community hospital practice: management strategies, complications, and outcomes. J Neuroimaging 22:233-242, 2012

23. Johnston SC: Effect of endovascular services and hospital volume on cerebral aneurysm treatment outcomes. Stroke 31: 111-117, 2000

24. Kramer AA, Zimmerman JE: The relationship between hospital and intensive care unit length of stay. Crit Care Med 39: 1015-1022, 2011

25. Langham J, Reeves BC, Lindsay KW, van der Meulen JH, Kirkpatrick PJ, Gholkar AR, et al: Variation in outcome after subarachnoid hemorrhage: a study of neurosurgical units in UK and Ireland. Stroke 40:111-118, 2009 


\section{Caseload and outcome in $\mathrm{SAH}$}

26. Lawton MT, Du R: Effect of the neurosurgeon's surgical experience on outcomes from intraoperative aneurysmal rupture. Neurosurgery 57:9-15, 2005

27. Leake CB, Brinjikji W, Kallmes DF, Cloft HJ: Increasing treatment of ruptured cerebral aneurysms at high-volume centers in the United States. Clinical article. J Neurosurg 115:1179_ 1183,2011

28. McDougall CG, Spetzler RF, Zabramski JM, Partovi S, Hills NK, Nakaji P, et al: The Barrow Ruptured Aneurysm Trial. Clinical article. J Neurosurg 116:135-144, 2012

29. Molyneux AJ, Kerr RS, Yu LM, Clarke M, Sneade M, Yarnold JA, et al: International subarachnoid aneurysm trial (ISAT) of neurosurgical clipping versus endovascular coiling in 2143 patients with ruptured intracranial aneurysms: a randomised comparison of effects on survival, dependency, seizures, rebleeding, subgroups, and aneurysm occlusion. Lancet 366: 809-817, 2005

30. Naso WB, Rhea AH, Poole A: Management and outcomes in a low-volume cerebral aneurysm practice. Neurosurgery 48: 91-100, 2001

31. Natarajan SK, Sekhar LN, Ghodke B, Britz GW, Bhagawati $\mathrm{D}$, Temkin N: Outcomes of ruptured intracranial aneurysms treated by microsurgical clipping and endovascular coiling in a high-volume center. AJNR Am J Neuroradiol 29:753-759, 2008

32. Nuño M, Patil CG, Lyden P, Drazin D: The effect of transfer and hospital volume in subarachnoid hemorrhage patients. Neurocrit Care 17:312-323, 2012

33. Pierot L, Spelle L, Vitry F, AETNA Investigators: Similar safety in centers with low and high volumes of endovascular treatments for unruptured intracranial aneurysms: evaluation of the analysis of treatment by endovascular approach of nonruptured aneurysms study. AJNR Am J Neuroradiol 31: 1010-1014, 2010

34. Rahme RJ, Veznedaroglu E, Batjer HH, Bendok BR: Case volumes in vascular neurosurgery: potential implications for comprehensive stroke center designation. Neurosurgery 71:N25N26, 2012
35. Showstack JA, Rosenfeld KE, Garnick DW, Luft HS, Schaffarzick RW, Fowles J: Association of volume with outcome of coronary artery bypass graft surgery. Scheduled vs nonscheduled operations. JAMA 257:785-789, 1987

36. Solomon RA, Mayer SA, Tarmey JJ: Relationship between the volume of craniotomies for cerebral aneurysm performed at New York state hospitals and in-hospital mortality. Stroke 27: 13-17, 1996

37. Stroup DF, Berlin JA, Morton SC, Olkin I, Williamson GD, Rennie D, et al: Meta-analysis of observational studies in epidemiology: a proposal for reporting. Meta-analysis Of Observational Studies in Epidemiology (MOOSE) group. JAMA 283:2008-2012, 2000

38. Taylor CL, Yuan Z, Selman WR, Ratcheson RA, Rimm AA: Mortality rates, hospital length of stay, and the cost of treating subarachnoid hemorrhage in older patients: institutional and geographical differences. J Neurosurg 86:583-588, 1997

39. van Lindert EJ, Böcher-Schwarz HG, Perneczky A: The influence of surgical experience on the rate of intraoperative aneurysm rupture and its impact on aneurysm treatment outcome. Surg Neurol 56:151-158, 2001

40. Vespa P, Diringer MN: High-volume centers. Neurocrit Care 15:369-372, 2011

41. Whisnant JP, Sacco SE, O'Fallon WM, Fode NC, Sundt TM Jr: Referral bias in aneurysmal subarachnoid hemorrhage. J Neurosurg 78:726-732, 1993

Manuscript submitted March 29, 2013.

Accepted September 5, 2013.

Please include this information when citing this paper: published online October 4, 2013; DOI: 10.3171/2013.9.JNS13640.

Address correspondence to: Hieronymus D. Boogaarts, M.D., Department of Neurosurgery, Radboud University Nijmegen Medical Centre, Reinier Postlaan 4, Nijmegen 6500 HB, The Netherlands. email: h.boogaarts@nch.umcn.nl. 